\title{
Environmental Influence and Health Status of Elderly
}

\author{
Renu Tyagi ${ }^{1}$, Satwanti Kapoor ${ }^{1, *}$ and A.K. Kapoor ${ }^{2}$ \\ ${ }^{I}$ Department of Anthropology, University of Delhi, Delhi-110007, India and ${ }^{2}$ Vice Chancellor, Jiwaji University, Gwal- \\ ior-474011, M.P., India
}

\begin{abstract}
The study was conducted in order to explore and compare the health status of the elderly living in two different environmental setups. Height, weight, heart rate and blood pressure were measured in 259 subjects ranging from 60-85 years. This process includes 120 elderly from old age homes and 139 elderly living with their families. Body mass index was calculated statistically. Nutritional status was assessed using the BMI guidelines of WHO.

Significant differences were found in weight, heart rate, blood pressure and BMI between most of the age groups of old age homes and females living with families. Percentage of overweight/obesity was found to be relatively higher among females living with families as compared to those living in old age homes. The blood pressure showed positive and significant association [p<0.01] with the BMI. The cardiovascular functions [p<0.001] and nutritional status [p<0.05] were found to be significantly influenced by the environmental set up.
\end{abstract}

Key Words: Ageing, old age homes, nutritional status, adiposity, cardio-vascular health.

\section{INTRODUCTION}

An increasing proportion of elderly people in India and similar trends in other countries indicate a need for more attention towards them. Life expectancy of males in India is 63.9 years and that of females is 66.9 years [1]. A higher proportion of females with comparison to males in 60 years and above category demands an additional focus towards the elderly women. A transition of traditional joint family system to the nuclear families has given rise to the concept of institutionalization or old age homes in India as well. There are more than 1012 old age homes (all types of institutions included) in India [2] and their number is continuously increasing. There are two types of Old Age Homes in India. One is the "Free" type which cares for the destitute old people who have no one else to take care for them. They are given shelter, food, clothing and medical care. The second type is the "Paid" home where care is provided through payment. Four main reasons for shifting to old age homes were reported to be the poverty, no support from the children, no one to take care fo and loneliness [3].

Advancing age pose a challenge to morphological and physiological function of man. Old age is associated with ill health, physical and sensory impairment, heightened sensitivity and increased susceptibility to the diseases [4]. Ageing is a series of parallel process related to one another [5].

Obesity, a global epidemic, is found to be associated with increased risk of disease morbidity and mortality [6]. There are more than 300 million obese people worldwide and there is an increase of 100 million in this number since 1995 [7]. Body composition i.e., the relative and absolute amount of

\footnotetext{
*Address correspondence to this author at the Department of Anthropology, University of Delhi, Delhi-110007, India; Tel: 011-27667329; Fax: 01127666614; E-mail: satwanti@yahoo.com
}

lean body mass and depot fat is one of the most variable characteristics of the organism. It undergoes changes throughout life. Body composition is affected by age, sex, race, genes and numerous environmental and behavioural factors [8]. It is not only the quantity of fat but the way it is distributed end up in more health complications. With advancing age, the regional adiposity, as assessed by the Waist Hip Ratio (WHR) was found to increase consistently with age $[9,10]$ whereas BMI does not show such consistency with age. Indices of general adiposity i.e. Body Mass Index (BMI) and Grand Mean Thickness (GMT) were found to increase till the sixth decade of life thereafter it declined however, the regional adiposity (WHR) showed an increase with age thereby redistribution of fat with age in favour of central adiposity was reported among females [11] which has epidemiological implications.

There are certain changes in the nutritional status of the body and dietary intake with age. Elderly become vulnerable to malnutrition owing to inappropriate dietary intake, poor economic status and social deprivation [12]. Anthropometric measurements are often used to assess the nutritional status of individual and community [13]. The Body mass index (BMI) is the most established indicator for assessment of adult nutritional status [14]. The BMI has also been widely used as a practical measure of chronic energy deficiency [15]. Both underweight and overweight constitute adult malnutrition. So there is a need to study the proportion of both underweight and overweight to assess the malnutrition caused due to both excess and less fat in the body.

Studies on old age home residents are very few and even those studies also focus the social $[16,17]$, psychological $[18,19]$ profile of the elderly. Research with reference to biological characteristics of the elderly people in India highlighting comparative assessment of elderly in old age homes and families are non-existent. 
Elderly especially females being major segment of total population and most vulnerable group need more attention. The present paper is an attempt to study an influence of environment on health status as assessed from biological indices among female senior citizens living in two different environmental set ups.

\section{METHODS}

A total number was of 259 subjects studied. This included 120 elderly females from the old age homes coded as $\mathrm{OAH}$ (old age home females) and 139 elderly females living within the families coded as FLF (Females living with families), respectively.

An approval of the ethical committee of the Institution was obtained to start the present study. A well-informed oral consent of each subject was also taken prior to start the study. The subjects ranged from 60-85 years of age. The subjects were divided into three age groups namely 60-70 years, 71-80 years and 81 years and above. A door-to-door survey was conducted for the elderly staying in the family set up. Sample for the old age home category was collected from six different old age homes located in Delhi. The three old age homes onto were available on charity basis (St. Mary's Home, Home for the Aged, Deendayal Upadhayay Vridhashram) and rest three were there on pay and stay basis (Sandhya Home for Senior Citizens, Arya Mahila Ashram and Anand Niketan Vridhashram).

Stature, body weight, heart rate and blood pressure were calculated. Stature, body weight were taken following the standard recommended techniques [20]. Nutritional status was studied using World Health Organisation, BMI guidelines [7]. Mean, SD, t-test was computed. Pearson Correlation coefficients were used to study the relationship between nutritional status and cardio-vascular functions in two different environment set ups.

\section{RESULTS}

The females living with families (FLF) belonged to lower-middle socio-economic class with an annual income of Rs. 48,000 (USD 1180). Annual income of the females in the OAH was Rs. 60,000 (USD 1475). Dietary habits for both the groups studied were mixed type i.e. including both vegetarian and non-vegetarian diet. The life styles of the elderly in old age homes and of those in the families differed markedly with respect to dietary habits, physical activity, medical and health care. The subjects staying in the old age homes had more regular diet, periodic medical health check ups and a higher exercise level than their family living counterparts who had relatively irregular diet, involved in most of the household activities, and visited physician only in the case of need or emergency. Rate of literacy was high among elderly women staying in the old age homes.

Table 1 showed demographic characteristics of the subjects. The proportion of females staying in old age homes was found to be highest in the 71-80 years age group however, among females staying in the family set up, highest number of subjects was found in 60-70 years group.

The basic data of the females staying in two different environment setups shown in Table 2 . The family living females were found to be taller as compared to $\mathrm{OAH}$ females.

Table1. Distribution of Subjects

\begin{tabular}{|c|c|c|}
\hline Age Group & Old Age Home Females [OAH] & Females Staying in the Family Set Up [FLF] \\
\hline \hline $60-70$ years & 26 & 58 \\
\hline $71-80$ years & 56 & 52 \\
\hline 81 yrs \& above & 38 & 139 \\
\hline Total & 120 & 52 \\
\hline
\end{tabular}

Table 2. Characteristics of Females

\begin{tabular}{|c|c|c|c|c|c|c|}
\hline \multirow{2}{*}{ Subjects (n) } & \multicolumn{2}{|c|}{ Stature $[\mathrm{cm}]$} & \multicolumn{2}{|c|}{ Weight [kg] } & \multicolumn{2}{|c|}{ BMI } \\
\hline & Mean \pm SD & $\mathbf{t}$ & Mean \pm SD & $\mathbf{t}$ & Mean \pm SD & $\mathbf{t}$ \\
\hline $60-70$ years OAH [26] & $148.14 \pm 6.86$ & & $59.36 \pm 14.03$ & & $22.68 \pm 4.71$ & \\
\hline $60-70$ years FLF [58] & $151.03 \pm 6.19$ & $2.89 *$ & $58.02 \pm 12.52$ & 1.34 & $22.55 \pm 4.88$ & 0.12 \\
\hline 71-80years OAH [56] & $146.91 \pm 6.48$ & & $54.12 \pm 11.41$ & & $22.16 \pm 3.69$ & \\
\hline 71-80years FLF [29] & $149.82 \pm 6.56$ & $2.90 *$ & $58.29 \pm 11.46$ & $4.17 * * *$ & $21.80 \pm 4.06$ & 0.36 \\
\hline 81 yrs \& above OAH [38] & $144.06 \pm 5.65$ & & $47.88 \pm 11.20$ & & $19.22 \pm 2.82$ & \\
\hline 81 yrs \& above FLF [52] & $146.37 \pm 5.85$ & 2.30 & $54.73 \pm 12.53$ & $6.85 * * *$ & $22.85 \pm 4.09$ & $3.63^{*}$ \\
\hline
\end{tabular}

$\mathrm{OAH}-\mathrm{Old}$ age homes females; FLF- Females living with families.

$* \mathrm{p}<0.05 ; * * * \mathrm{p}<0.001$. 
Table 3. Cardio-Vascular Variables Among Females

\begin{tabular}{|c|c|c|c|c|c|c|}
\hline Subjects [n] & \multicolumn{2}{|c|}{$\begin{array}{c}\text { Heart Rate } \\
\text { [b/min] }\end{array}$} & \multicolumn{2}{|c|}{$\begin{array}{c}\text { Systolic Blood Pressure } \\
{[\mathrm{mmHg}]}\end{array}$} & \multicolumn{2}{|c|}{$\begin{array}{c}\text { Diastolic Blood Pressure } \\
{[\mathrm{mmHg}]}\end{array}$} \\
\hline $60-70$ years OAH [30] & $77.31 \pm 8.31$ & & $137.31 \pm 27.30$ & & $87.69 \pm 17.08$ & \\
\hline 60-70 years FLF [57] & $79.38 \pm 10.60$ & 2.07 & $125.96 \pm 17.92$ & $11.34 * * *$ & $82.69 \pm 11.71$ & $4.99^{* * * *}$ \\
\hline 71-80years FLF [55] & $77.72 \pm 11.25$ & 0.35 & $130.96 \pm 17.88$ & 2.18 & $88.69 \pm 11.03$ & $9.29 * * *$ \\
\hline 81 yrs \& above OAH [10] & $79.21 \pm 13.44$ & & $132.05 \pm 24.65$ & & $81.69 \pm 14.23$ & \\
\hline 81 yrs \& above FLF [31] & $77.69 \pm 9.55$ & 1.52 & $129.15 \pm 15.81$ & $2.89 *$ & $78.47 \pm 12.24$ & $3.22 * *$ \\
\hline
\end{tabular}

OAH- Old age homes females; FLF- Females living with families.

${ }^{*} \mathrm{p}<0.05 ; * * \mathrm{p}<0.01 ; * * * \mathrm{p}<0.001$

The differences in the mean value of height were found to be significant in 60-70 years and 71-80 years age group. A significantly higher body weight was found among females staying with the family in the 71-80 years and $81 \&$ above year age group but a non-significant but higher body weight was found among 60-70 years OAH females than FLF.

Table 3 shows the cardio-vascular variables among elderly females. The heart rate was found to be higher among $\mathrm{OAH}$ females than in FLF in 71-80 years and 81 years \& above age group however, the differences were found to be statistically non-significant. Blood pressure both systolic and diastolic, were found to be significantly higher among $\mathrm{OAH}$ females as compared to FLF in 60-70 years and 81 years \& above females, though reverse trend was found in 71-80 years age group females.

Percentage of chronic energy deficiency was found to be higher among females in the OAH (10\%) than in the FLF $(8.62 \%)$ however, a higher percentage of normal subjects were also found in the OAH than in the family set up. Percentage of overweight/obesity was found to be higher in the family set up i.e. among FLF than the females staying in the old age homes (Fig. 1).

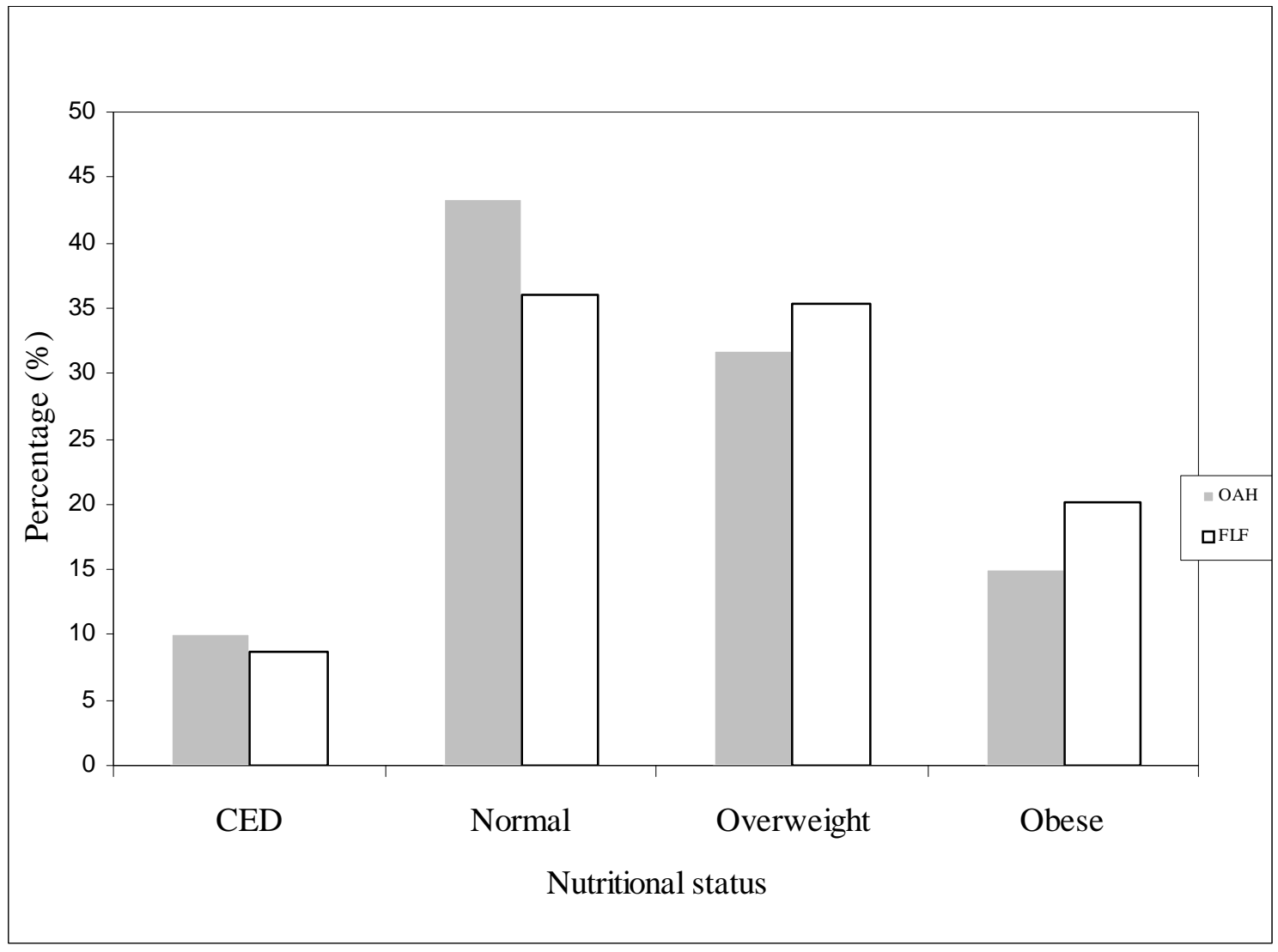

Fig. (1). Distribution of subjects according to nutritional status based on BMI. 
Statistically significant and positive associations $(\mathrm{p}<0.05)$ were found between the blood pressure and BMI among females in both the groups (Table 4).

Table 4. Correlation Coefficients of Cardiovascular Variables with BMI

\begin{tabular}{|c|c|}
\hline Variables & BMI \\
\hline \hline HR & 0.009 \\
\hline SBP & $0.174^{*}$ \\
\hline DBP & $0.182^{*}$ \\
\hline
\end{tabular}

$* \mathrm{p}<0.01$.

\section{DISCUSSION}

Statistically significant differences were obtained for stature and weight between FLF and OAH females. The females staying in family set up were found to be significantly taller than their counterparts staying in the old age homes. The females in the OAH were found to have lower body weight in 71-80 years and $81 \&$ above age group than females staying with the families. Significant differences were found for the cardiovascular measurements between $\mathrm{OAH}$ females and FLF in all the age groups indicating a strong influence of environment on these variables especially blood pressure. Blood pressure showed a non-linear relationship with age in both the environmental set up in the present study and similar findings were reported by some workers $[21,22]$. Whereas other workers $[23,24]$ reported both systolic and diastolic blood pressure to increase with age. Significant lower blood pressure was found in 60-70 years and 81 years \& above age groups of females living in the family set up as compared to females in the old age homes. Besides loneliness and poor social network in the old age home, staying in the old age homes is taken as a stigma by the society and the elderly themselves. These factors may generate more stress /tension among the inhabitants of the old age homes which is reflected in their high blood pressure levels as compared to FLF.

The percentage of chronic energy deficiency (CED) is found to be relatively higher among OAH females than their counterparts staying with the families. The chronic energy deficiency is likely to be associated with morbidity and other functional impairments $[14,7]$. Dietary inadequacies among the elderly may have important health implications as there is a strong association between nutrition and many degenerative diseases [12]. A higher percentage of normal subjects in the OAH group indicated their regular food habits and better physical activity level than the females staying in the families. The Old age home females had a higher educational level so their awareness about health was more as well.

The percentage of overweight/obesity was found to be lower in the OAH than the senior citizens staying with the families. A better physical activity profile and diet restriction reported among the $\mathrm{OAH}$ females are probably the main causes of the lower percentage of overweight/obesity in the former group. An essential role of modest diet with increased physical activity during the life span was reported to be an important component of long living population among different populations of the world [25].

The BMI showed positive association with the blood pressure among females in the present study. A study [26] in developing and developed countries showed a linear relationship of adiposity with blood pressure independent of age and body fat distribution. Another study [27] also found a positive correlation between the blood pressure and body composition.

\section{CONCLUSION}

Shifting to old age homes has been found to have an influence on health status of the subjects as the subjects staying in the old age homes were found to be less overweight/obese and higher percentage belonged to normal weight category (nutritional status) as compared to those staying with the families thereby indicating a positive impact of Old age homes on the nutritional status of the subjects. But the psychological stress of staying away from the families is clearly reflected in deviance of the cardiovascular functions among old age home females.

\section{ACKNOWLEDGEMENTS}

The authors are thankful to all the subjects for their kind cooperation for the present study. The Fellowship by Department of Science and Technology, to Renu Tyagi is greatly acknowledged.

\section{REFERENCES}

[1] Census of India. Office of Registrar General and Census Commissioner, India, 2001.

[2] HelpAge India. Directory of old age home in India. Help Age India, regional office, Delhi, India, 2002.

[3] Bansood D, Paswan B. From home to old age home: A situational appraisal of elderly in old age home in Maharashtra. Res Dev J 2006; 12: 14-24.

[4] Birren JE, Schaic KW. Handbook of Psychology of Aging. N.Y. Van Nostrand. Reinhold 1996; pp. 130-135.

[5] Siniarska A, Wolanski N. Ecology of Aging. Kamla Raj Enterprises, New Delhi, India, 2000.

[6] Lapidus L, Bengstsson C, Larsson B, Penerrt K, Rybo E, Sjostrom L. Distribution of adipose tissue and risk of cardiovascular disease and death: a 12-year follow up of participants in the population study of women in Gothenburg, Sweden. Br Med J 1984; 289: 1257-61.

[7] World Health Organisation. Physical status: the use and interpretation of anthropometry. Technical report series. No. 854, Geneva: World Health Organisation 1995.

[8] Chumlea WC, Baumgarter RN. Status of Anthropometry and Body Composition Data In Elderly Subjects. Am J Clin Nut 1989; 50: 1158-66.

[9] Kapoor S, Tyagi R. Fatness, fat pattern and changing body dimensions with age in adult males of a high altitude population: In Science of man in service of man, Bhasin MK, Malik SL, Eds. Kamla Raj Enterprises publications, Delhi, India 2002.

[10] Sinha R, Kapoor S. Sensitivity of various skinfold sites to fat distribution in adolescent daughters and their mothers. Acta Biol Szeged 2007; 51 (1): 21-25.

[11] Tyagi R, Kapoor S, Kapoor AK. Body composition and fat distribution pattern of urban elderly females, Delhi, India. Colleg Antropol 2005; 29(2): 493-98.

[12] Wadhwa A, Sabharwal S, Sharma S. Nutritional status of the elderly. Ind J Med Res 1997; 106: 340-48.

[13] Brahmam GNV. Nutritional Status of The Aged In Public Health Implication of Aging in India New Delhi. Ind J Med Res 1994; $92-$ 98.

[14] James WPT, Ferro-Luzzo A, Waterlow IC. Definition of Chronic Energy Deficiency In Adults, Report of a working party of the in- 
ternational dietary energy consultative group. Eur J Clin Nut 1988; 42: 969-81.

[15] Khongsdier R. BMI and morbidity in relation to body composition: a cross-sectional study of rural community in north east India. Br J Nut 2005; 93: 101-07.

[16] Ara S. Old Age Homes and the profile of their residents. Ind J Med Res 1997; 106: 409-12.

[17] Patri VR. A comparison of self concept of the elderly residing in an institutionalized setting: An empirical study. In Ageing- Indian perspectives and global scenario, Kumar V, Ed. AIIMS, New Delhi, India 1996; pp 272-274.

[18] Arora M, Chaddha NK. Social support and life satisfaction of institutionalized elderlies. Ind J Gerontol 1995; 9(3 \& 4): 74-82.

[19] Dhillon PK, Samat S. Emotional status of the instituionalized Aged. In: Psycho-social aspects of ageing in India, New Delhi: Dhillon PK, Ed. Concept publishing Company, India 1992, pp. 215240

[20] Weiner JS, Lourie JA.Human Biology- A guide to field methods. I.B.P. handbook no.9, Blackwell Scientific Publication, Oxford, 1981.
[21] Tyagi R, Kapoor S. Morpho-Physiological Changes with age among high attitude females. Man In India 1999; (1\&2): 173-178

[22] Tyagi R, Kapoor S. Ageing in structural and functional dimensions among institutionalized and non -institutionalized senior citizens. Anthropol Int J Sci 2004; XL112 (2): 141-46

[23] Nirmala A, Reddy PC. A study of blood pressure on aged. In: Life in Twilight years. Quality Book Publishers, Calcutta, India 1997; Pp 223-228.

[24] Tungdim MG, Kapoor S, Kapoor AK. Morpho-physiological changes among high altitude aged. Ind J Gerontol 2002;16(3-4): 329-343.

[25] Parizkova J. The effort of the interrelationship between diet and physical activity on aging. In: Ecology of Aging. Kamla Raj Enterprises, New Delhi, India 2000, pp. 31-42.

[26] Doll S, Paccaud F, Bovet P, Burnier M, Wietlisbach V. Body mass index, abdominal adiposity and blood pressure. Consistency of their association across developing and developed countries. Int $\mathbf{J}$ Obes 2002; 26(1): 48-57.

[27] Sambasiva Rao R. Blood Pressure and Triceps Skinfold Thickness. Annal Hum Biol 1983; 10: 191-93.

(C) Tyagi et al.; Licensee Bentham Open.

This is an open access article distributed under the terms of the Creative Commons Attribution License (http://creativecommons.org/licenses/by/2.5/), which permits unrestrictive use, distribution, and reproduction in any medium, provided the original work is properly cited. 